\title{
The Effectiveness of Mindfulness-Based Cognitive Therapy on Severity of Social Anxiety and Self-Control People with Social Anxiety Symptoms
}

\author{
Fatemeh Hatamian \\ M.A Clinical Psychology, Department of Clinical Psychology, Najafabad Branch, Islamic Azad University, Najafabad, Iran \\ Maryam Ghorbani*
}

Assistant Professor In Psychology, Department of Psychology, Payame Noor University, Tehran, Iran, PO BOX: 19395-3697

*Corresponding Author: ghorbani_psyc@yahoo.com

\author{
Doi:10.5901/mjss.2016.v7n4s2p231
}

\begin{abstract}
This study was conducted to assess the effectiveness of mindfulness-based cognitive therapy on severity of social anxiety and self-control people with social anxiety symptoms. The study was quasi-experimental with pretest - posttest and follow-up with experiential groups. The population consisted of all the students at Isfahan University, Iran. However, 30 students from this university were randomly placed into two groups namely experimental and control groups (15 students in each group). The used inventory in this research was: 1. Liebowitz Social Anxiety Scale (Liebowitz, 1987) and Self-control questionnaire (Tangney, 2005). The results of MANOVA test showed that mindfulness-based cognitive-behavioral therapy in reducing severity of social anxiety and improvement of self-control and psychological flexibility is effective in patients with social anxiety symptoms $(p$ < 0.01). According to the results of this research, mindfulness-based cognitive-behavioral therapy is an effective way to improve the factors that can have an important role in improving social anxiety.
\end{abstract}

Keywords: Mindfulness-based Cognitive Therapy, Self-control, Social anxiety symptoms.

\section{Introduction}

During the last two decades, social anxiety disorder has gradually been known as one of the most prevalent psychological chronic disorders, and the most prevalent anxiety disorder (Sosic, Gieler, Stangier, 2008). In severe cases, social anxiety can reduce the quality of life for the person to the extent that some of the patients might refuse to leave home for weeks, or waiver many social opportunities such as occupational or educational ones (Heimberg, Stein, Hiripi, Kessler, 2000). Epidemiology studies report that the prevalence of social anxiety is 3 to 13 percent. A 13-percent prevalence puts this disorder in the third position of psychological disorders in the society after depression and alcoholism (Kessler, McGonagleZhao, Nelson, Hughes, Eshleman, Wittchen, 1994). It is a type of disorder which usually results in a long period of disability (Bruce, Yonkers, Otto, Eisen, Weisberg, 2005) and the patients suffer significant damage if their daily social and professional life (Reich, Hofmann, 2004). Social anxiety or fear of embarrassment in functional or social situations is the most prevalent anxiety disorder which affects the adult functioning at home or at work (Haikal \& Hong, 2010, Higa \& Daleiden, 2008). It has weakening effects and is one the most common psychological disorders with a prevalence lifespan of 3 to 13 percent (Kessler, Chiu, Demler \& Walters, 2005). Various genetic factors, personal characteristics, and cognitive-behavioral elements play a role in social anxiety; how the total outcome of these factors form this disorder is what considered in the prediction of its outbreak and severity (Starcevic, 2005). Many variables are related to social anxiety that could be a factor or an outcome of this disorder. One issue related to managing one's emotional reactions to others is self-control (Greaves \& Bradberry, 2005, Gangi, translator, 2005). Self-control is intrapersonal conflict between logic and lust, cognition and motivation, and internal planning and internal functor. It is an important concept which determines an individual's behavior, and a force for inhibition, rejection, and modification of responses that are a consequence of psychological processes, habits, learning, or situational pressure (Schmeichel, Vohs \& Baumeister, 2004). Self-control, to the most part, is a result of parental discipline in childhood (Aghababaei, Khanzadeh, Hemmati Alamdarloo, Moradi, and Rezaei, 2008). In fact, a significant part of psychological pathology in children and adults is about insufficiency of self-control (Logue, 1995). Self-control in childhood has various positive outcomes in adulthood, such as less delinquency, reduced drug use, improved sexual performance, higher education, and better job opportunities. However, the intervention of other factors - gender, economic and social conditions, IQ, and 
childhood conduct disorder - in the relationship between self-control and the aforementioned outcomes should be noted as well (Carver, 2013, Nedelec, Beaver, 2014).

In any case, social anxiety has severe negative effects on psychological, personal, and social health of patients (Gerlach, 2003). High levels of unemployment (Wittchen\& Beloch, 1996), absence from work (Garcia-Lopez, 2006), and low quality of life (Acarturk, 2008), are socio-economic outcomes of this disorder. In addition, anxiety, anger, hostility, verbal aggression, and borderline tendencies are cases which have negative significant correlation with self-control (Kabat-Zinn, 2014). For example, Tangie, Bumster, and Bune (2004) showed that university students with high selfcontrol show better psychological adjustment and do better in interpersonal relations (quoted by Hamidi, 2009).

Among recently emerged treatments in the area of cognition in psychology is Mindfulness-Based Cognitive Therapy (MBCT). Mindfulness is a type of consciousness formed when there is open attention to experience around a specific subject, a focused attention on the target (openly on specific aspects of experience) in the present and without judgment (about what has happened) $(9,1994)$. Mindfulness-based cognitive therapy was developed from Kabat-Zinn's model of mindfulness-based stress reduction with cognitive treatment principals added to it later. This type of cognitive therapy includes different meditations, stretch yoga, an introduction to depression, practicing body review, and a number of cognitive therapy exercises, that show the relationship between creation, thoughts, emotions, and physical senses (Younesi and Rahimial Bogar, 2008). Mindfulness-based cognitive therapy, which is a non-judgmental process of attention to the present experience (Desrosiers, Klemanski, Nolen-Hoeksema, 2013), has been widely incorporated into the treatment of a range of psychological disorders such as depression and anxiety (دسروسير et al. 2013). Studies on treatment outcomes have supported the effectiveness of mindfulness-based cognitive therapy on depression and anxiety (Hofmann, Sawyer, Witt, Oh, 2010).

This therapy, which is a short-term 8-session structured intervention, is based on Kabat-Zinn's model of mindfulness stress reduction (1990) (quoted by Mark G. Williams and Michaela Swales, 2004) with added cognitive therapy principles. The goal here is not to manipulate thoughts, but to create a different attitude towards thoughts, emotions, and feelings. This encompasses full open attention on the moment, as well as non-judgmental acceptance (Wells, 2002).

Mindfulness-based cognitive therapy includes a number of different techniques derived from mindfulness mechanisms (Hölzel, Lazar, Gard, Schuman-Olivier, Vago and Ott, 2011). Many studies have offered suggestions for a more targeted application of mindfulness techniques based on specific signs of depression and anxiety (Keng, Smoski, Robins, 2011). Additionally, mindfulness-based cognitive therapy includes five prevalent mechanisms (Baer et al. 2006, Baer et al. 2008, Fernandez, Wood, Stein \& Rossi, 2010): 1. Description. The ability to describe internal experiences by words, 2. Observation. The process of observing or paying attention to internal and external experiences. 3. Mindfulness action: doing current activities at the present is usually compared with acting automatically, 4. Lack of judgment: accepting a non-judgmental point of view towards thoughts and emotions, 5. Lack of reaction: letting thoughts and emotions to come and go without reacting or trying to amend them.

The mechanism of MBCT against anxiety cognitive patterns includes: 1) decentralization (the ability to focus on the present and being non-judgmental about thoughts and feelings, and accepting them), and 2) changing the state of doing to the state of being (this is a key component of MBCT which helps patients to decentralize. The state of doing includes thinking a lot about past and future, and not being in the present. However, the state of being is a state of no effort and no judgment. Decentralization is similar to the mind's state of being. The state of doing is when there is a difference between how things are and they are supposed to be, as determined by the mind (Fresco, Moore, van Dulmen, Segal, Teasdale \& Williams, 2007).

Christopher et al. (2012) showed that a positive relationship exists between mindfulness-based cognitive mechanisms and symptoms of depression and anxiety. Barnhofer, Chittka, Nightingale, Visser and Crane (2011), De Bruin et al. (2012), Cash and Whittingham (2010), and Vujanovic, A. A., Youngwirth, Johnson \& Zvolensky (2009) also showed reduced anxiety symptoms with mindfulness-based cognitive therapy. Bernstein, Tanay and Vujanovic (2011) found that learning mindfulness-based cognitive skills reduces anxiety. A study by Fisak and von Lehe (2012) reported that in mindfulness-based cognitive therapy, being non-responsive reduces anxiety. This is because letting thoughts and feelings to enter consciousness, without reacting to them or trying to amend them (i.e. worry and rumination), is useful for reducing continuous negative thought processes which are prevalent in the anxiety disorder. De Bruin, Topper, Muskens, Bogels, and Kamphuis (2012) also showed that mindfulness-based cognitive therapy reduces worry and rumination.

Regarding the effectiveness of mindfulness-based cognitive therapy on social anxiety and self-control, no study has been conducted so far in Iran. Therefore, this study aims to answer the question that whether mindfulness-based cognitive therapy (MBCT) affects anxiety and self-control in patients with social anxiety. 


\subsection{Hypotheses}

1. Mindfulness-based cognitive therapy affects social anxiety symptoms in patients with social anxiety.

2. Mindfulness-based cognitive therapy affects self-control in patients with social anxiety.

\subsection{Research methodology}

The present study was quasi-experimental with pre-test post-test and follow-up with experiential groups.

\subsection{Population, sample, and sampling method}

The research population was the students of Isfahan University. Using the social anxiety scale test, the students with social anxiety were diagnosed. At the end, 30 students were selected through purposive sampling, and were randomly divided into experimental and control groups. The selection criteria was: a score of greater than 70 in Liebowitz Social Anxiety Scale (LSAS), no chronic diseases like MS, no cardiovascular diseases, no psychological illnesses such as bipolar disorder and psychosis, and no addiction. The criteria for eliminating a participant was: being absent for more than two intervention sessions, and lack of consent for receiving therapy.

Table 1. The ultimate sample based on age and gender

\begin{tabular}{|c|c|c|c|c|}
\cline { 3 - 5 } \multicolumn{2}{c|}{} & \multicolumn{3}{c|}{ Gender } \\
\cline { 3 - 5 } \multicolumn{2}{c|}{} & Male & Female & Total \\
\hline \multirow{3}{*}{ Age } & $19-22$ & 8 & 8 & 16 \\
\cline { 2 - 5 } & $22-25$ & 5 & 9 & 14 \\
\cline { 2 - 5 } & Total & 13 & 17 & 30 \\
\hline
\end{tabular}

\section{Data Gathering Tools}

1. Liebowitz Social Anxiety Scale (LSAS): created by Liebowitz in 1987, it is the first medical tool that evaluates a wide range of social situations that are difficult to face with for social anxiety patients. It is a questionnaire with 24 items. Scoring 55 to 65 indicates low social anxiety, while 55 to 80 and 80 to 95 are indicators of average and sever social anxiety respectively. Scoring 95 or more shows that the person suffers from highly severe social anxiety. The reliability of this test has been evaluated through Chronbach's Alpha. The total Chronbach's Alpha for this scale is 0.95 , performance anxiety subscale Chronbach's Alpha is 0.82 , and social anxiety subscale Alpha is 0.91 . In order to evaluate its convergent validity, the test was compared to Social Interaction Anxiety Scale (Mattick and Clark, 1998). Liebowitz's correlations were between 0.40 and 0.77 , while correlations of Mattick and Clark were between 0.31 and 0.72 . Non-anxious subjects scored more in this test. Chronbach's Alpha in this study is 0.72 .

2. Self-control. This measure was made by Tangney (2004). It is a questionnaire with 36 items that is design based on Likert scale. In Iran, validity and reliability of this test was measured by Rafiei and Janbozorgi (2010), and they obtained a Chronbach's Alpha of 0.89. In addition, the re-test coefficient and Chronbach's Alpha of self-control questionnaire was 0.88 and 0.80 respectively, as measured and confirmed by Khanzadeh et al. (2009). Chronbach's Alpha in this study is 0.77 .

\section{Methodology}

Both groups took a pre-test of social anxiety and self-control. The experimental group received an 8-session mindfulnessbased cognitive therapy (MBCT) intervention. At the end, both groups took a post-test of the aforementioned variables. A follow-up test was given after one month and the results were analyzed.

A summary of mindfulness-based cognitive therapy (MBCT) is presented in table 2. 
Table 2. A summary of mindfulness-based cognitive therapy (MBCT)

\begin{tabular}{|c|c|c|c|}
\hline \multicolumn{2}{|c|}{ Session Duration } & Purpose & Summary \\
\hline First & 90 minutes & Concentration & $\begin{array}{l}\text { Introduction and overall outline of the program. Concentration practice through } \\
\text { meditation, breathing, and homework. }\end{array}$ \\
\hline Second & 90 minutes & $\begin{array}{l}\text { Consciousness/mindfulness for thoughts, } \\
\text { feelings, emotions, and physical senses }\end{array}$ & $\begin{array}{l}\text { Review of homework; defining mindfulness and explaining its importance; } \\
\text { Practicing proximity to emotional and sensory awareness; Homework. }\end{array}$ \\
\hline Third & 90 minutes & Attention on the moment & $\begin{array}{l}\text { Review of homework; practicing attention on the present moment; meditation; body } \\
\text { checking; breathing; homework. }\end{array}$ \\
\hline Fourth & 90 minutes & Decentralization & $\begin{array}{l}\text { Review of homework; defining decentralization with practicing decentralization } \\
\text { components; patients practice decentralization of thoughts and emotion (or any } \\
\text { event) during meditation sessions; meditation, breathing, and homework. }\end{array}$ \\
\hline Fifth & 90 minutes & $\begin{array}{l}\text { Acceptance, no aversion, no attachment, } \\
\text { awareness with acceptance }\end{array}$ & $\begin{array}{l}\text { Review of homework; defining acceptance concepts including "experiencing events } \\
\text { completely, as they are, without defense" and values; practice, meditation, } \\
\text { breathing, homework. }\end{array}$ \\
\hline Sixth & 90 minutes & Release & $\begin{array}{l}\text { Review of homework; taking the required steps together with meditation, breathing, } \\
\text { and homework. }\end{array}$ \\
\hline Seventh & 90 minutes & Non-targeted being & $\begin{array}{l}\text { Review of homework; reviewing the concept of being instead of doing; being non- } \\
\text { targeted; not searching for a specific state (relaxation, happiness, calmness, ...); } \\
\text { meditation, breathing, homework. }\end{array}$ \\
\hline Eight & 90 minutes & $\begin{array}{l}\text { Being aware of physical problems, } \\
\text { aversions, and stresses }\end{array}$ & $\begin{array}{l}\text { Review of homework; becoming aware of problems with physical manifestation, } \\
\text { together with seeking for aversions and stresses; meditation, breathing, and } \\
\text { homework; final words. }\end{array}$ \\
\hline
\end{tabular}

\section{Data analysis Method}

All data was given to SPSS 16 and described through descriptive statistics (mean and standard deviation). Assumptions were then analyzed through covariance analysis.

\section{Findings}

Table 3 shows the descriptive statistics index of social anxiety of subjects in experimental and control groups in pre-test, post-test, and follow-up.

Table 3. Descriptive statistics index of social anxiety of subjects in experimental and control groups in pre-test, post-test, and follow-up

\begin{tabular}{|l|l|c|c|c|}
\hline Group & Evaluation stage & Number & Standard error & Mean \\
\hline \multirow{4}{*}{ Experimental } & Pre-test & 15 & 7.57 & 85.06 \\
\cline { 2 - 5 } & Post-test & 15 & 6.91 & 76.53 \\
\cline { 2 - 5 } & Follow-up & 15 & 6.84 & 82.40 \\
\hline \multirow{4}{*}{ Control } & Pre-test & 15 & 7.33 & 83.33 \\
\cline { 2 - 5 } & Post-test & 15 & 6.83 & 77.06 \\
\cline { 2 - 5 } & Follow-up & 15 & 7.14 & 81.73 \\
\hline
\end{tabular}

As shown in table 3, mean social anxiety in the experimental group was 4.80 in pre-test, 4.25 in post-test, and 4.66 in follow-up. Mean social anxiety in the control group was 4.05 in pre-test, 4.12 in post-test, and 4.18 in follow-up. Table 4 shows the results of homogeneity test for variance and covariance based on the scores of social anxiety pre-test.

Table 4. The results of homogeneity test for variance \& covariance based on the scores of social anxiety pre-test.

\begin{tabular}{|c|c|c|c|c|}
\hline Box & $F$ & Degree of freedom 1 & Degree of freedom 2 & Significance \\
\hline 0.743 & 0.229 & 3 & 0.001 & 0.877 \\
\hline
\end{tabular}

As table 4 shows, homogeneity of covariance of scores of social anxiety pre-test was confirmed $(p>0.05)$. Table 5 shows the results of homogeneity test for variances of self-control post-test and follow-up scores. 
Table 5. The results of homogeneity test for variances of self-control post-test and follow-up scores.

\begin{tabular}{|l|c|c|c|c|}
\hline Evaluation stage & $\mathrm{F}$ & Degree of freedom 1 & Degree of freedom 2 & Significance \\
\hline Post-test & 2.608 & 1 & 28 & 0.118 \\
\hline Follow-up & 1.799 & 1 & 28 & 0.191 \\
\hline
\end{tabular}

As table 5 shows, the homogeneity of variance of scores of social anxiety post-test and follow-up is confirmed ( $p>0.05)$.

Table 6 shows the results of Shapiro-Wilk test for social anxiety.

Table 6. The results of Shapiro-Wilk test for social anxiety

\begin{tabular}{|c|c|c|c|}
\hline & Statistic & Number of participants & Significance \\
\hline Social anxiety & 0.957 & 30 & 0.670 \\
\hline
\end{tabular}

According to the results of Shapiro-Wilk test in table $6(p>0.05)$, we can, with a high level of confidence, assume that the data is normal. Table 7 shows the results of covariance analysis for evaluating the effectiveness of mindfulness-based cognitive therapy on social anxiety of subjects in terms of their group and the stage of evaluation.

Table 7. The results of covariance analysis for evaluating the effectiveness of mindfulness-based cognitive therapy on social anxiety of subjects in terms of their group and the stage of evaluation.

\begin{tabular}{|c|c|c|c|c|c|c|c|c|c|}
\hline $\begin{array}{l}\text { Source of } \\
\text { changes }\end{array}$ & $\begin{array}{c}\text { Dependent } \\
\text { variable }\end{array}$ & $\begin{array}{c}\text { Stage of } \\
\text { evaluation }\end{array}$ & $\begin{array}{l}\text { Sum of } \\
\text { squares }\end{array}$ & $\begin{array}{c}\text { Degree of } \\
\text { freedom }\end{array}$ & $\begin{array}{l}\text { Mean } \\
\text { square }\end{array}$ & $\mathrm{F}$ & Significance & $\begin{array}{l}\text { Size of effect } \\
\text { (percent) }\end{array}$ & $\begin{array}{c}\text { Statistical } \\
\text { power }\end{array}$ \\
\hline \multirow[b]{2}{*}{ Pre-test } & \multirow{2}{*}{$\begin{array}{c}\text { Behavioral } \\
\text { inhibition }\end{array}$} & Post-test & 555.116 & 1 & 555.116 & 12.510 & 0.000 & 19.51 & 0.83 \\
\hline & & Follow-up & 463.451 & 1 & 463.451 & 13.625 & 0.001 & 13.62 & 0.85 \\
\hline \multirow{2}{*}{$\begin{array}{l}\text { Group mem- } \\
\text { bership }\end{array}$} & \multirow{2}{*}{$\begin{array}{c}\text { Behavioral } \\
\text { inhibition }\end{array}$} & Post-test & 352.171 & 1 & 352.171 & \begin{tabular}{|l|}
12.378 \\
\end{tabular} & 0.004 & 12.37 & 0.97 \\
\hline & & Follow-up & 232.884 & 1 & 232.884 & 6.846 & 0.014 & 6.84 & 0.98 \\
\hline
\end{tabular}

The results of variance analysis in table 7 show that by controlling significant relationships between pre-test scores and post-test and follow-up scores of social anxiety $(p<0.01)$, the difference between the justified mean of experimental and control groups at post-test $(p<0.01)$ and follow-up $(p>0.05)$ is significant. Regarding justified means of the two groups, it can also be concluded that mindfulness-based cognitive intervention has reduced behavioral inhibition by $12.37 \%$ in post-test, and $6.8 \%$ in follow-up. In addition, the statistical power of $97 \%$ shows the sufficiency of the sample and the acceptability of statistical accuracy.

Table 8. Justified means of social anxiety of subjects in terms of group membership and the stage of evaluation

\begin{tabular}{|l|c|c|c|c|}
\hline \multirow{2}{*}{ Group } & \multicolumn{2}{|c|}{ Post-test } & \multicolumn{2}{c|}{ Follow-up } \\
\cline { 2 - 5 } & Mean & Standard deviation & Mean & Standard deviation \\
\hline Experimental & 79.46 & 0.97 & 82.00 & 1.73 \\
\hline Control & 82.45 & 1.38 & 83.73 & 1.88 \\
\hline
\end{tabular}

As is shown in table 8, justified mean of social anxiety of the experimental group is 79.46 in post-test and 82.00 in followup, and that of the control group is 82.45 and 83.73 respectively. Table 9 shows the descriptive statistics of self-control for subjects in both groups and in all tests.

Table 9. Descriptive statistics of self-control for experimental and control groups in pre-test, post-test, and follow-up

\begin{tabular}{|l|l|c|c|c|}
\hline Group & Evaluation stage & Number of participants & Standard error & Mean \\
\hline \multirow{3}{*}{ Experimental } & Pre-test & 15 & 34.55 & 113.00 \\
\cline { 2 - 5 } & Post-test & 15 & 3.71 & 105.67 \\
\cline { 2 - 5 } & Follow-up & 15 & 36.58 & 116.47 \\
\hline \multirow{3}{*}{ Control } & Pre-test & 15 & 36.33 & 116.13 \\
\cline { 2 - 5 } & Post-test & 15 & 30.65 & 107.60 \\
\cline { 2 - 5 } & Follow-up & 15 & 107.60 & 116.93 \\
\hline
\end{tabular}


As presented in table 9, mean score of self-control in the experimental group was 113.00, 105.67, 116.47 in pre-test, post-test, and follow-up respectively. In the control group it was 116.13, 107.60, and 116.93 in pre-test, post-test, and follow-up respectively. Table 10 shows the results of homogeneity test for variance and covariance according to selfcontrol pre-test scores.

Table 10. The results of homogeneity test for variance and covariance according to self-control pre-test scores.

\begin{tabular}{|c|c|c|c|c|}
\hline Box & $F$ & Degree of freedom 1 & Degree of freedom 2 & Significance \\
\hline 1.52 & 0.469 & 3 & 0.01411 & 0.704 \\
\hline
\end{tabular}

As table 10 shows, homogeneity of covariance of scores of self-control pre-test was confirmed $(p>0.05)$. Table 11 shows the results of homogeneity test for variances of self-control post-test and follow-up scores.

Table 11. The results of homogeneity test for variances of self-control post-test and follow-up scores.

\begin{tabular}{|l|c|c|c|c|}
\hline Evaluation stage & $\mathrm{F}$ & Degree of freedom 1 & Degree of freedom 2 & Significance \\
\hline Post-test & 3.451 & 1 & 28 & 0.074 \\
\hline Follow-up & 2.898 & 1 & 28 & 0.100 \\
\hline
\end{tabular}

As table 11 shows, the homogeneity of variance of scores of self-control post-test and follow-up is confirmed $(p>0.05)$.

Table 12 shows the results of Shapiro-Wilk test for self-control.

Table 12. The results of Shapiro-Wilk test for self-control

\begin{tabular}{|c|c|c|c|}
\hline & Statistic & Number of participants & Significance \\
\hline Self-control & 0.934 & 30 & 0.054 \\
\hline
\end{tabular}

According to the results of Shapiro-Wilk test in table $12(p>0.05)$, we can, with a high level of confidence, assume that the data is normal. Table 13 shows the results of covariance analysis for evaluating the effectiveness of mindfulnessbased cognitive therapy on self-control in subjects in terms of their group and the stage of evaluation.

Table 13. The results of covariance analysis for evaluating the effectiveness of mindfulness-based cognitive therapy on self-control in subjects according to their group and the stage of evaluation.

\begin{tabular}{|c|c|c|c|c|c|c|c|c|c|}
\hline $\begin{array}{l}\text { Source of } \\
\text { changes }\end{array}$ & $\begin{array}{c}\text { Dependent } \\
\text { variable }\end{array}$ & $\begin{array}{c}\text { Stage of } \\
\text { evaluation }\end{array}$ & $\begin{array}{l}\text { Sum of } \\
\text { squares }\end{array}$ & $\begin{array}{c}\begin{array}{c}\text { Degree of } \\
\text { freedom }\end{array} \\
\end{array}$ & $\begin{array}{c}\text { Mean } \\
\text { square }\end{array}$ & $\mathrm{F}$ & tance & $\begin{array}{c}\text { Size of effect } \\
\text { (percent) }\end{array}$ & $\begin{array}{c}\begin{array}{c}\text { Statistical } \\
\text { power }\end{array} \\
\end{array}$ \\
\hline \multirow{2}{*}{ Pre-test } & \multirow{2}{*}{$\begin{array}{c}\text { Behavioral } \\
\text { inhibition }\end{array}$} & Post-test & 30166.334 & 1 & 30166.334 & 457.39 & 0.000 & 94.4 & 1 \\
\hline & & Follow-up & 28390.003 & 1 & 28390.003 & 365.27 & 0.000 & 93.1 & 1 \\
\hline \multirow{2}{*}{$\begin{array}{c}\text { Group mem } \\
\text { bership }\end{array}$} & \multirow{2}{*}{$\begin{array}{c}\text { Behavioral } \\
\text { inhibition }\end{array}$} & Post-test & 467.009 & 1 & 467.009 & 7.08 & 0.013 & 20.8 & 0.82 \\
\hline & & Follow-up & 318.09 & 1 & 318.09 & 4.09 & 0.053 & 13.2 & 0.74 \\
\hline
\end{tabular}

The results of variance analysis in table 13 show that by controlling significant relationships between pre-test scores and post-test and follow-up scores of social anxiety $(p<0.01)$, the difference between the justified mean of experimental and control groups at post-test $(p<0.01)$ and follow-up $(p<0.05)$ is significant. Regarding justified means of the two groups, it can also be concluded that mindfulness-based cognitive intervention has reduced self-control by $20.8 \%$ in post-test, and $13.2 \%$ in follow-up. In addition, the statistical power of $82 \%$ shows the sufficiency of the sample and the acceptability of statistical accuracy.

Table 14. Justified means of self-control in subjects according to their group and the stage of evaluation

\begin{tabular}{|l|c|c|c|c|}
\hline \multirow{2}{*}{ Group } & \multicolumn{2}{|c|}{ Post-test } & \multicolumn{2}{c|}{ Follow-up } \\
\cline { 2 - 5 } & Mean & Standard deviation & Mean & Standard deviation \\
\hline Experimental & 107.12 & 2.098 & 109.02 & 2.27 \\
\hline Control & 115.21 & 2.098 & 115.50 & 2.27 \\
\hline
\end{tabular}


As is shown in table 14, justified mean of self-control of the experimental group is 107.12 in post-test and 109.02 in follow-up, and that of the control group is 115.21 and 115.50 respectively.

\section{Discussion}

The first hypothesis - mindfulness-based cognitive therapy affects the level of anxiety in social anxiety patients - was confirmed. The results showed that this treatment improves social anxiety in these patients. This finding conforms to the findings of a number of other studies: Gonzalez, Vajanwick, Johnson, Laier, and Volenski (2009), Abramson et al. (2002), and fisak and Van le (2012) suggested that mindfulness-based cognitive therapy reduces anxiety. That is because letting thoughts and feelings enter consciousness without reacting to them or trying to amend them is useful for reducing negative thoughts that are prevalent in both depression and anxiety. Debrion, Taper, Masenz, Bogelz, and Comfemis (2012) also showed that mindfulness-based cognitive therapy reduces worry and rumination. This finding was confirmed by Fisk et al. (2012), and De Bruin et al. (2012). On the other hand Gerlach et al. (2003) showed that social anxiety has severe negative effects on the psychological, personal, and social health of the patients. In this respect, the two main mechanisms of MBCT against cognitive anxiety patterns includes: 1) decentralization (the ability to focus on the present with no judgment about thoughts and feelings; the state of accepting), and 2) being instead of doing (changing the state of doing to the state of being is a key component of MBCT which helps patients to decentralize) (Fresko, Segal, Bayes, and Kennedy, 2007). In fact, mindfulness-based interventions with the purpose of reducing psychological symptoms of distress (Kabat, 1990) are increasingly applied in the field of psychological health (Gerousmen, 2011). The aim of these interventions is to create a clear non-judgmental mindfulness about everything happening in the perception at any consecutive moment. Most of the time, psychological suffering can be traced back to the judgmental mind which divides experiments into good ones and bad ones, and dictates that one should fight or avoid, and therefore, a range of negative feelings such as failure, distress, anxiety, and depression (Micky Leak, 2008). By reducing the presence of judgmental mind and decentralizing, we can reduce worry and anxiety. The major skill learnt when practicing mindfulness is to release oneself from rumination, negative thoughts, and self-continuation, which are part of the state of doing. In the state of being, the focus is on accepting whatever present at the moment, without trying to change anything. In the state of being, there is no effort for analyzing future outcomes, finding solutions for potential problems, or reviewing previous efforts for solving similar problems. Instead of thinking about problems or situations, in the state of being one tries to directly observe and accept whatever happening in the present, including thoughts and feelings which require instant action. This mindfulness attitude towards thoughts and feelings, slows down reactivity against others, and increases the ability to choose new answers. It also increases rumination, reinforces acceptance of thoughts and feelings, and weakens the tendency to consider these thoughts and feelings as necessarily precise reflections of the truth about self or the world. Therefore, using these new skills, one can experience sadness without automatically intensifying anxiety.

The second hypothesis - mindfulness-based cognitive therapy affects self-control in patients with social anxiety was confirmed. The results showed that this treatment improves self-control in these patients. This conforms to findings of a number of other studies. For example, Rasoul Zadeh (2014) studied cognitive therapy based on acceptance and commitment. The results showed reduced social anxiety and improved assertiveness and inconsistent beliefs, as well as the justifying role of emotional regulation. The theoretical implications of these findings are worth noting, since no other study has specifically considered self-control. Therefore, since self-control determines one's behavior, it is a force of inhibition, rejection, and change of responses as a result of psychological processes, habits, learning, or situational pressures $(1,2004)$. One of the major problems in social anxiety is experimental avoidance (an activity to change the form, the content, the frequency, or the duration of an unwanted personal experiment (Hayes and Giford, 1997). This experimental avoidance manifests itself in to forms: escaping from annoying experiments or distancing from situations related to the initiation of those mental experiments, and behavioral suppression. This avoidance can temporarily reduce anxiety and its symptoms, however, it has long-term negative social, psychological, and even physical effects (Hayes, 2004). Kobat Zinn (1992) suggested a number of approaches regarding the potential effects of mindfulness on anxiety and fear: constantly monitoring the senses related to anxiety, without judgment and without trying to escape or avoid, can reduce emotional reactions that were invoked by anxiety. As Linhan (1993) pointed out in his study, patients with borderline personality disorder suffer from emotional phobia; these people are frightened to experience severely negative emotions. This fear is understandable, since their negative emotional states are generally intense. However, their effort to avoid these states usually has inconsistent outcomes. Observing present thoughts and emotions, without trying to avoid them, can be a kind of confrontation that prevents fear responses and automatic reactions reinforced by fear-provoking stimuli; therefore, the ability to tolerate negative emotions has positive effects that will in turn produce more adaptability and better social relationships. In this respect the results of Tangie, Bumster, and bunn (2004) indicate that university 
students with higher self-control show better adaptability and interpersonal relationships; they also do better in their studies (quoted by Hamidi, 2009).

Mindfulness helps people to understand that negative emotions might exist, but they are not a permanent part of personality. It also provides an opportunity to respond to events with thinking and reflection, rather than involuntarily (Emanuel et al. 2010). This type of awareness enables patients to see the provoking of rumination and negative reactions more clearly, and can decentralize such thinking patters, and see them as mental processes not representative of the truth (Mikey, 2008). Ultimately, it helps the person to discover calmness and satisfaction in the deep of herself, and to bring it into her daily life; it helps the person to gradually free herself from worry, anxiety, fatigue, depression, and dissatisfaction. Without mindfulness, the person will experience exhausting emotions mixed with bitter feelings, anger, and severe insolvency (Williams and Penman, 2012). It is justifiable by mindfulness-based therapy, that regarding avoidance behavior against social situations, patients tend to consider short-term consequences of avoiding internal and external stimuli, which leads to negative reinforcement, and suffer the long-term consequences such as continuity and intensification.

According to the results of the present study, it is suggested that in treating social anxiety patients, mindfulness main processes and skills, together with other interventions such as awareness, decentralization, and releasing be specifically taken into account by therapists. Regarding self-control, it is suggested that therapists use emotional regulation approaches in order to regulate responses related to fear and worry in social anxiety. For better adaptation and better interpersonal relationships (that play an important role in improving social anxiety), it is also suggested that teaching communication skills be considered as part of the treatment.

\section{References}

Abramson LY, Alloy LB, Hankin BL, Haeffel GJ, MacCoon DG, Gibb BE.( 2002) Cognitive vulnerability-stress models of depression in a self-regulatory and psychobiological context. In: Gotlib IH, Hammen CL, editors. Handbook of depression. New York: Guilford Press;. pp. 268-294.

Acarturk C, Graaf de R, Straten van A, Have MT, Cuijpers P (2008) Social Phobia and number of social fears, and their association with comorbidity, health-related quality of life and help seeking: A population-based study. Social Psychiatry Epidemiology 43: 273279.

Aghababaei, H., Khanzadeh, A., Hemmati Alamdarlou, G., Moradi, A., Rezaei, S. (2011). Predicting Self-Control Capacity through Various Religious Orientations and Its role in Reducing Delinquency. Journal of Criminal Law. 2, 2: 19-36.

Baer, R.A., Smith, G.T., Hopkins, J., Krietemeyer, J., \& Toney, L.(2006). Using self-report assessment methods to explore facets of mindfulness. Assessment, 13, 27-45.

Baer, R.A., Smith, G.T., Lykins, E., Button, D., Krietemeyer, J., Sauer, S., Walsh, E.,Duggan, D., Williams, J.M. (2008). Construct validity of the five facet mindfulness questionnaire in meditating and nonmeditating samples. Assessment, 15, 329-342.

Barnhofer, T., Chittka, T., Nightingale, H., Visser, C., \& Crane, C.(2010). State effects of two forms of meditation on prefrontal EEG asymmetry in previously depressed individuals. Mindfulness (N Y), 1, 21-27.

Bernstein, A., Tanay, G., \& Vujanovic, A. A. (2011). Concurrent relations between indful attention and awareness and psychopathology among trauma-exposed adults: Preliminary evidence of transdiagnostic resilience. Journal of Cognitive Psychotherapy, 25, 99113.

Bradberry, T., and Griour, G. (2005). Emotional Intelligence Test. Ganji, M. Translator. Tehran: Savalan.

Bruce, S. E., Yonkers, K. A., Otto, M. W., Eisen, J. L., Weisberg, R. B., Pagano, M., Shea, M. T., \& Keller, M. B. (2005). Influence of psychiatric comorbidity on recovery and recurrence in generalized anxiety disorder, social phobia, and panic disorder: A 12-year prospective study. American Journal of Psychiatry, 162, 79-87 .

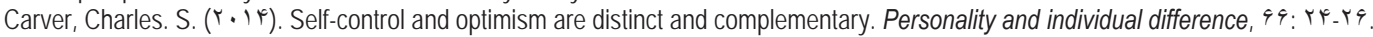

Cash M, Whittingham K.( 2010) What facets of mindfulness contribute to psychological well-being and depressive, anxious, and stressrelated symptomatology? Mindfulness.; 1:177-182

Christopher, M. S., Neuser, N. J., Michael, P. G., \& Baitmangalkar, A. (2012). Exploringthe psychometric qualities of the Five Facet Mindfulness Questionnaire .Mindfulness, 3, 124-131. doi: 10.1007/s1267-011-0086-x

De Bruin El, Topper M, Muskens JGAM, Bogels SM, Kamphuis JH. (2012).Psychometric properties of the five facets mindfulness questionnaire (FFMQ) in a meditating and anon -meditating sample.

Desrosiers A, Klemanski DH, Nolen-Hoeksema S.(2013). Mapping mindfulness facets onto dimensions of anxiety and depression. Behavior Therapy.44(3):373-84

Fergusson, David. $M$ and Boden, Joseph. $M$ and Harwood, I. john. $(r+1 r)$. childhood self- control and adult outcome results from a $r \cdot$ year longitudinal study. American academy of child \& adolescent psychiatry, or $(\vee): \vee \cdot १-\vee \backslash \vee$.

Fernandez, A. C., Wood, M. D., Stein, A. R., \& Rossi, J. S. (2010). Measuring mendfulness and examining its relationship with alcohol use and negative consequences.Psychology of Addictive Behaviours, 24(4), 68-616.

Fisak B, von Lehe AC.( 2012) The relation between the five facets of mindfulness and worry in anon-clinical sample. Mindfulness. 3:1521 
Fresco, D.M., Moore, M.T., van Dulmen, M.H., Segal, Z.V., Ma,S.H., Teasdale, J.D., \& Williams, J.M. (2007). Initial sychometric properties of the experiences questionnaire: Validation of a self-report measure of decentering. Behavior Therapy, 38,234-246.

Garcia-Lopez, L.J.; Olivares, J.; Beidel, D.; Albano, A.M.; Turner, S.; Rosa, A.L.(2006).Efficacy Of Three Treatment Protocols For Adolescents With Social Phobia: A 5- Year Follow - Up Assessment. Journal of Anxiety Disorders

Gerlach, A.L.; Willielm, F.H.; Roth, W.T(2003). Economic Costs Of Social Phobia: A Population - Based Study. Journal Of Affective Disorders. Vol. Xx; P.P. Xxx-Xxx.

Grossman $\mathrm{P}(2011)$. Defining mindfulness by how poorly I think I pay attention during everyday awareness and other intractable problems for psychology's (re) invention of mindfulness: Comment on Brown et al.Psychological Assessment; 23:1034-1040

Haikal, M. \& Hong, R. Y. (2010). The effects of social evaluation and looming threat on self-attentional biases and social anxiety. Journal of Anxiety Disorders, 24, 345-352.

Hamidi, S. (2009). The Effect of Teaching Personal Capabilities (Consciousness and Self-Control) on Reduced Internet Addiction in Female Students of Kamyaran. Master's Thesis. Allameh Tabatabei University.

Heimberg RG, Stein MB, Hiripi E, Kessler RC (2000). "Trends in the prevalence of social phobia in the United States: a synthetic cohort analysis of changes over four decades". Eur. Psychiatry 15 (1): 29-37.

Higa, C. K., \& Daleiden, E. L. (2008). Social anxiety and cognitive biases in non-referred children: the interaction of self-focused attention and threat interpretation biases. Journal of Anxiety Disorders, 22, 441-452.

Hofmann SG, Sawyer AT, Witt AA, Oh D (2010). The effect of Mindfulness-Based Therapy on anxiety and depression: a meta-analytic review. Journal of Consulting and Clinical Psychology 78, 169-183

Hölzel B,. Lazar S, Gard T, Schuman-Olivier Z, Vago and Ott U.(2011). How Does Mindfulness Meditation Work? Proposing Mechanisms of Action From a Conceptual and Neural Perspective. Perspectives on Psychological Science. 6: 537

Kabat-Zinn, J. (1994). Wherever you go, There you are: Mindfulness meditation in everyday life. New York: Hyperion.

Keng, S., Smoski, M., Robins, C. (2011). Effects of mindfulness on psychological health: A review of empirical studies. Clinical Psychology Review, 31, 1041-1056. doi:10.1016/j.cpr.2011.04.006

Kessler, R. C., Chiu, W. T., Demler, O., \& Walters, E. E. (2005). Prevalence, Severity, and Comorbidity of 12-Month DSM-IV Disorders in the National Comorbidity Survey Replication. Archives of General Psychiatry, 62(6), 617-627.

Kessler, R. C., McGonagle, K. A., Zhao, S., Nelson, C. B.,Hughes, M., Eshleman, S., Wittchen, H. U. (1994). Lifetime and 12-month prevalence of DSM-III-R.psychiatric disorders in the United States: Results from the National Comorbidity Survey. Journal of General Psychiatry, 51, 8-19.

Logue, A. W. (1995). Self-control: Waiting until tomorrow for what you work today. Englewood Cliffs, NJ: Prentice Hall

Mark G. Williams and Michaela Swales .(2004). The Use of Mindfulness-Based Approaches for Suicidal Patients. Archives of Suicide Research, 8:315-329.

Mattick, R. P. \& Clarke, J. C. (1998). Development and validation of measures of social phobia scrutiny fear and social interaction anxiety. Behavior Research and Therapy 36, $455 \pm 470$.

Nedelec, joseph. L., Beaver, Kevin. M. $\left(r_{+}, Y^{\digamma}\right)$. The relationship between self- control in adolescence and social consequence in adulthood assessing the influence of genetic confounds. Criminal justice. $r$ r $(r): \curlyvee \wedge \wedge$ - $৭ \wedge$.

Rafiei Honar, H., Janbozorgi, M. (2010). The Relationship between Religious Orientation and Self-Control. Journal of Psychology and Religion. 1, 42, 9.

Reich, J., Hofmann, S. G. (2004). State personality disorder in social phobia. Journal of Annals of Clinical Psychiatry, 16,139-144.

Schmeichel, B.J., Vohs, K.D., \& Baumeister, R.F. (2003). Intellectual performance and ego depletion: Role of the self in logical reasoning and other information processing. Journal of Personality and Social Psychology ,85, 33-46

Sosic,Z.,Gieler,U.,Stangier,U.(2008).Screening for social phobia in medical in and outpatients with German version of social phobia Inventory(SPIN). Journal of anxiety Disorders.,.22; 849-859

Starcevic, V. (2005). social anxiety disorder (social piobia). In an anxiety disorders in adults: a clinical guide. 1st edition. Oxford university press. 141-190.

Tangney, J. P., Baumeister, R. F., \& Boone, A. L.(2004). High Self-Control Predicts Good Adjustment, Less athology, Better Grades, and Interpersonal Success. Journal of Personality 72(2),272-324.

Vujanovic, A. A., Youngwirth, N. E., Johnson, K. A., \& Zvolensky, M. J.(2009).Mindfulness-based acceptance and posttraumatic stress symptoms among trauma exposed adults without axis I psychopathology. Journal of Anxiety Disorders, 23,297-303.

Wells, A. (2002). GAD, Metacognition, and mindfulness: An information processing analysis. Clinical Psychology: Science and Practice, 9(1), 95-100.

Wittchen, H.-U. \& Beloch, E. (1996). The impact of social phobia on quality of life. International Clinical Psychopharmacology 11 (suppl.3), 15-23.

Younesi, S.J., Rahimian Bogar, E. (2008). A Window to Metacognition. Tehran: Danjeh publication. 